\title{
Surface phenomena accompanying plasma gouging of S355 steel
}

\author{
Anatol Kałasznikow ${ }^{1, *}$, and Mariusz Michalski ${ }^{2}$ \\ ${ }^{1}$ AK ANATOL, 4 Handlowa Street, 68200 Żary, Poland \\ ${ }^{2}$ Faculty of Mechanical Engineering, University of Zielona Gora, 4 Prof. Z. Szafrana Street, 65516 Zielona Gora, Poland
}

\begin{abstract}
The paper presents the results of investigation of surface changes taking place after the process of gouging with air plasma. The investigation included the assessment of the plasma current influence on the structure and hardness of metal sheets with the thickness of 6,12 and $16 \mathrm{~mm}$. It has been found that, in the process of gouging, both the value of the plasma stream intensity and the thickness of the material significantly influence the properties of the top layer and the size of the formed grooves. The existence of two surface zones has been proved: the zone of melted metal and the heat affected zone. It has been determined that increase of the plasma stream intensity, with constant sheet thickness, results in an increase of the gouging depth. . It has been proven that the increase the sheet thickness for constant plasma currents influence for decrease in the depth of the gouging grooves.
\end{abstract}

\section{Introduction}

Plasma gouging is a process of making a groove on a metal surface with the use of plasma arc. The heat of the plasma arc arising between the electrode and the object being processed rapidly melts the metal and the gas from the nozzle blows off the melted semi-automatic or automatic (CNC) device for plasma cutting. Plasma cutters can be provided with the gouging mode but the process can be affected in the cutting mode, too (with adequate selection of parameters).

In the process cutting, as well as in that of plasma gouging, the material under the process is subjected to both thermal action (plasma arc) and mechanical one (gas pressure). Such action, with additionally occurring high cooling speeds, results in modification of the structure and properties of the top layer of the material being processed.

Literature survey shows that plasma cutting of unalloyed and low-alloy steels results in formation of three zones with different properties. The first one is the zone of melted metal (MM), the second one is the heat affected zone (HAZ) and the third one is the zone with the structure of the basic material. The melted metal zone - white layer [1] has hard-to-etch structure of high hardness and brittleness [2]. In that zone (about $20 \mu \mathrm{m}$ thick), changes of the chemical composition (as compared to the initial material) can be observed, as well as saturation of metal with gases (mainly nitrogen when cutting with the use of air plasma) [2, 3]. In works [4, 5], an effect of strong hardening of the layer situated near the surface of cutting performed with air plasma has been observed. In microscopic inspections, microanalysis and x-ray examinations, the presence of phases $\varepsilon\left(\mathrm{Fe}_{2} \mathrm{~N}\right)$ and $\gamma$ ' $\left(\mathrm{Fe}_{4} \mathrm{~N}\right)$ has been found. The heat affected zone is also characterized with high hardness which gradually decreases towards the core to obtain the hardness of the basic material. In the case of cutting unalloyed and low-alloy steels (with various thicknesses), the use of air plasma results in formation of heat affected zone with an average thickness of about $0.6-0.7 \mathrm{~mm}[1,6,7]$. However, increase of the sheet thickness results in structure changes and increase of hardness in the heat affected zone. This effect can be explained by the increased cooling speed resulting from the heat conduction by the material core. In work [8], plasma cutting of S355 steel has been used as an example to prove that the thickness of the heat affected zone depends directly on the cutting speed and the distance from the cutting edge. Incrise of cutting speed result in the SWC decrise. It has also been determined that the thickness of the heat affected zone increases with the increase of the distance from the top cutting edge.

Both in the process of machining, cutting and plasma gouging, there is a hazard of micro cracks at the processed surfaces due to hard and brittle structure of the heat affected zone [2,9]. In such case, subsequent processes or dynamic loads can initiate development of cracks and, consequently, lead to failure of elements. In order to prevent it, the layer susceptible to cracking should be removed $[2,10]$. This makes it very important to know the influence of the plasma gouging or cutting parameters on the properties of the material being processed.

The theme of the plasma cutting on the properties of materials being processed is widely described in the

* Corresponding author: anatol@zsanatol.com.pl 
professional literature, however, there is shortage of data concerning plasma gouging.

Literature data imply that, in the case of plasma gouging, the authors concentrate on the problems related to the influence of the processing parameters on the shape and size of the formed grooves. Work [11], shows the possibility of using air plasma for gouging carbon steel as a cheaper alternative to the use of nitrogen.

Furthermore, the relationship between the groove shape and size and the gripping angle and scanning speed has been determined. The change of the groove shape from "U" to "V" takes place with reduction of the grip inclination angle and increase of the scanning speed. It has also been found that the presence of nitrides occurring on the surface of the gouged metal does not influence formation of gas porosity in the process of welding.

Work [10] uses alloy steel and argon - helium plasma with cooling gas in the form of argon to examine the influence of scanning speed and method (linear and oblique) and of the plasma current intensity on the depth of the gouged groove. It has been found that increase of the plasma current intensity results in an increase of the groove depth with an insignificant increase of its width.

The purpose of the present work was to determine the influence of the stream intensity in the process of plasma gouging on the structure and properties of S355JR steel with three different thicknesses.

\section{Materials and methods}

The test material used was unalloyed constructional steel grade S355JR in the form of a standard sheet with the thicknesses of 12 and $16 \mathrm{~mm}$.

The chemical composition of the steel and its designation have been shown in Table 1; an example of microstructure can be seen kin Fig. 1.

Table 1. Designation and chemical composition of the steel (max), \% wt. (acc. to PN-EN 10025).

\begin{tabular}{|c|c|c|c|c|c|}
\hline Steel & $\mathrm{C}$ & $\mathrm{Mn}$ & $\mathrm{Si}$ & $\mathrm{P}, \mathrm{S}$ & $\mathrm{N}$ \\
\hline $\begin{array}{c}\text { PN S355JR } \\
\text { EN 1.0045 }\end{array}$ & 0.24 & 1.6 & 0.5 & 0.045 & 0.009 \\
\hline
\end{tabular}

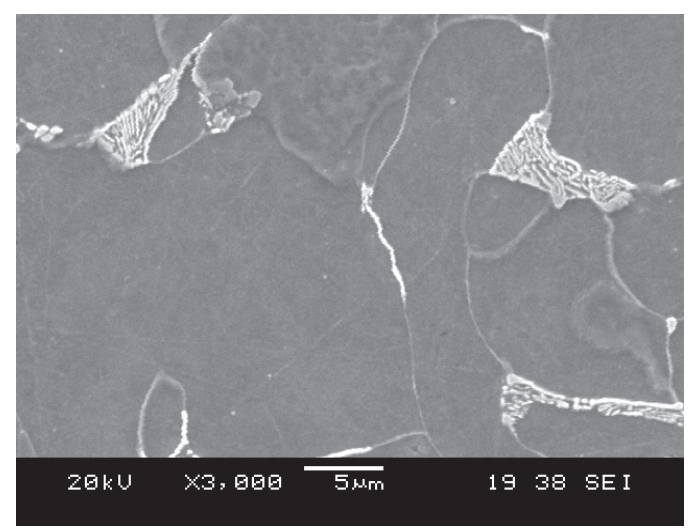

Fig. 1. Ferritic - pearlitic microstructure of the S355JR steel (scanning microscope).
The process of gouging has been performed with the use of a plasma cutting device with the working table size of $6000 \mathrm{x} 2000 \mathrm{~mm}$ with the plasma source, Formica ForCut133 WDM. The processing parameters have been selected to be constant for all the sheet thicknesses with only the plasma current intensity variable $(15,20,25 \mathrm{~A})$. The parameters of the plasma gouging process can be seen in Table 2.

Table 2. The parameters of gouging.

\begin{tabular}{|c|c|}
\hline The parameters of gouging & Sheet $6,12,16 \mathrm{~mm}$ \\
\hline Amperage, $\mathrm{A}$ & $15,20,25$ \\
\hline Arc voltage, $\mathrm{V}$ & 130 \\
\hline Speed of gouging, $\mathrm{mm} / \mathrm{s}$ & 66 \\
\hline Plasma gas & air \\
\hline Plasma gas pressure, $\mathrm{MPa}$ & 6,4 \\
\hline Cooling gas & air \\
\hline Cooling gas pressure, $\mathrm{MPa}$ & 2,2 \\
\hline Electrode & Hafnium (HF) \\
\hline Nozzle diameter, $\mathrm{mm}$ & 1 \\
\hline Torch distance, $\mathrm{mm}$ & 3 \\
\hline
\end{tabular}

The process of gouging the sheets consisted inn making parallel $100 \mathrm{~mm}$ long grooves on the sheet surfaces, at intervals of $5 \mathrm{~mm}$. For each of the three sheet thicknesses, three sets of samples have been made (for plasma current intensity of $15,20,25 \mathrm{~A}$; numbering in table3). The assessment of the obtained effects of gouging has been based on the samples taken in the form of cross sections of the gouged sheets. In order to perform metallographic examination, microsections have been prepared. Etching has been effected with the use of the chemical reagent, Nital $(3 \%$ water solution of $\mathrm{HNO}_{3}$ ). Microscopic examination has been performed with the use of an optical microscope, AxioObserver A1.m and a scanning microscope, Jeol 5600LV. Chemical composition has been assessed with the use of an x-ray microanalyzer, EDS, coupled to a scanning microscope. The HV0.1 microhardness has been measured with the use of a ZVICK ZHV-10 hardness tester, with the load of $100 \mathrm{~g}$.; indenter operation time $15 \mathrm{~s}$.

\section{Results and discussion}

The next subsections show the results of microscopic studies with the use of X-ray microanalysis and hardness measurements of samples.

\subsection{Microscopic examination}

The purpose of microscopic examination was to find structural changes of the material as result of plasma 
gouging and to determine the shape and size of the formed grooves.

The variable values of plasma current intensity applied in the subsequent experiments, as well various sheet thicknesses of the sheet subjected to plasma gouging have resulted in the acquisition of grooves with various shapes and dimensions. Microscopic examinations have allowed us to determine that the cross sections of the grooves consist of three zones: 1) melted metal, 2) heat affected zone. Fig. 2 shows examples of microstructures of the gougings under examination obtained for a $12 \mathrm{~mm}$ thick sheet, with variable plasma current intensity of 15, 20 and $25 \mathrm{~A}$, respectively.

a)

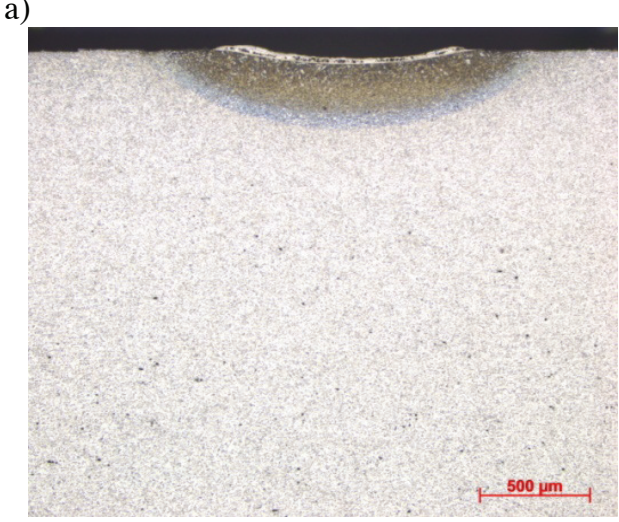

b)

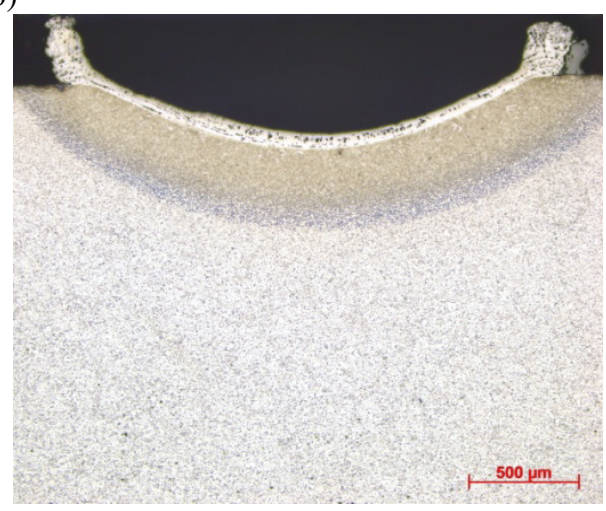

c)

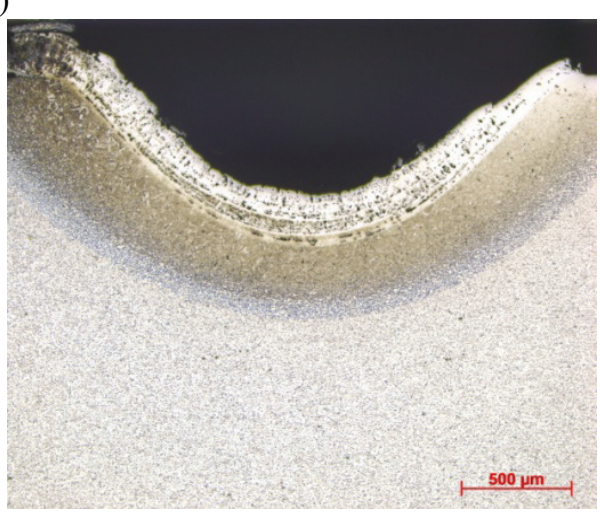

Fig. 2. Microstructure of the gouged steel sample with the thickness of $12 \mathrm{~mm}$, magnification $50 \mathrm{x}$. Plasma current intensity: a) $15 \mathrm{~A}$; b) $20 \mathrm{~A}$; c) $25 \mathrm{~A}$.

The groove size has been described in three dimensions: a) groove width $-\mathrm{s}(\mathrm{mm})$, b) groove depth $\mathrm{g}(\mathrm{mm}), \mathrm{c})$ melted layer thickness $-\mathrm{g}_{1}(\mathrm{~mm})$. The value of the groove width and depth is stated with the incorporation of the melted layer thickness. The groove size measurement results shown in table 2 are average values obtained from three grooves

Table 3. Assembled results of the gouged groove size measurements.

\begin{tabular}{|c|c|c|c|c|c|}
\hline $\mathrm{Nr}$ & $\begin{array}{c}\mathrm{b}, \\
\mathrm{mm}\end{array}$ & $\begin{array}{c}\text { Amperage, } \\
\text { A }\end{array}$ & $\begin{array}{c}\text { Groove } \\
\text { width, } \\
\text { mm }\end{array}$ & $\underset{\mathrm{mm}}{\text { Melted } \mathrm{g}_{1},}$ & $\begin{array}{c}\text { Groove } \\
\text { depth } \\
\mathrm{g}, \mathrm{mm}\end{array}$ \\
\hline 1 & \multirow{3}{*}{6} & 15 & 1.0 & 0,05 & 0,09 \\
\hline 2 & & 20 & 2,2 & 0,18 & 0,52 \\
\hline 3 & & 25 & 2,5 & 0,60 & 1 \\
\hline 4 & \multirow{3}{*}{12} & 15 & 1,0 & 0,04 & 0,06 \\
\hline 5 & & 20 & 2,1 & 0,07 & 0,35 \\
\hline 6 & & 25 & 2,3 & 0,2 & 0,83 \\
\hline 7 & \multirow{3}{*}{16} & 15 & 1 & 0,02 & 0,05 \\
\hline 8 & & 20 & 1,8 & 0,09 & 0,30 \\
\hline 9 & & 25 & 2,2 & 0,29 & 0,80 \\
\hline
\end{tabular}

Increase of the plasma current intensity (with the same sheet thickness) results in an increase of the dimensions of the melted metal zone and the heat affected zone, as well as the dimensions of the grooves themselves (Fig. 2). In accordance with Table 2, one can state that, with the same sheet thickness (and maximum plasma current intensity) the groove width grows over two times and its total depth increases grows even ten times. With the increase of the groove depth, thicker melted metal zone is obtained. In industrial conditions, this effect can be minimized by increasing the pressure of the auxiliary (cooling) gas or by increasing the nozzle inclination angle. Furthermore, the growth of the melted metal zone is accompanied by formation of characteristic flashes (Fig. 2). The investigation performed shows that the effects of gouging depend also on the thickness of the sheet under processing. Increase of the sheet cross section (in plasma gouging) causes an increase of the cooling speed (heat conduction through the material core), which results in obtaining grooves with smaller width and depth. The tests have also shown that that, gouging sheets of various thicknesses (with the same plasma current intensity) results in different sizes of the melted metal zone and heat affected zone. Increase of the sheet thickness (6 mm in Fig. 3 and $12 \mathrm{~mm}$ in Fig. 2c) causes reduction of the melted metal zone and the heat affected zone.

Microscopic examinations have revealed significant changes in the structure of the steels gouged with air plasma. In the samples in which the melted metal zone is 
in tye form of a thin layer (up to about $0.05 \mathrm{~mm}$ ), it constitutes a white layer.

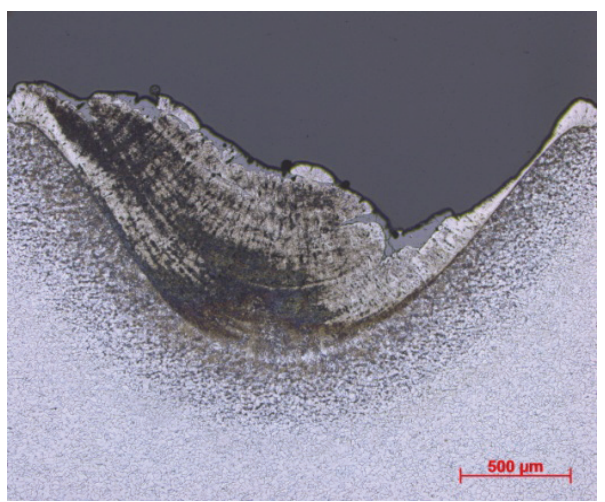

Fig. 3. Microstructure of the gouged $6 \mathrm{~mm}$ thick steel with the plasma current intensity of $25 \mathrm{~A}$, magnification $50 \mathrm{x}$.

The structure of that hard-to-etch layer consists of low carbon martensite and iron nitrides $[4,5]$. It is formed as result of high temperature influence of the air plasma on the top layer of the melted material and significant cooling of the liquid solution due to the intensive conduction of heat through the material core. In the analysis of the linear element distribution of a sample with revealed white layer (Fig. 4), it has been determined that formation of that layer is accompanied by an effect of its decarbonizing and nitriding.

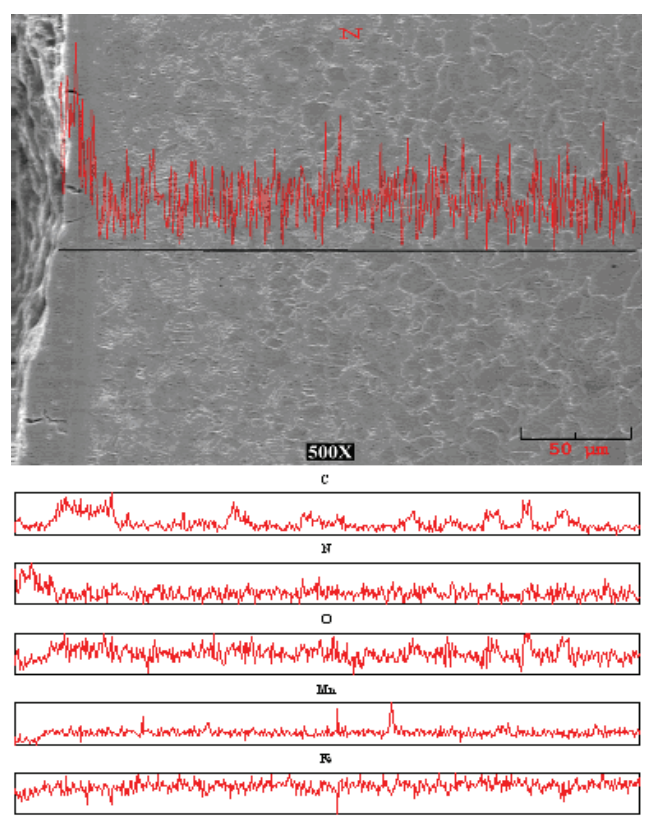

Fig. 4. Linear distribution of elements, $\mathrm{C}, \mathrm{N}, \mathrm{O}, \mathrm{Mn}$. Fe, on a cross section of a groove gouged in $6 \mathrm{~mm}$ thick steel with the current intensity of $15 \mathrm{~A}$.

With small thickness of the melted layer (low value of the plasma current intensity), short time of the gouged material heating, as well as quick cooling, significantly influence the degree of homogenization of austenite in the heat affected zone. In this case, homogenous martensitic structure appears only in the zone located directly under the zone of melted material (Fig. 5). The thickness of that layer depends on the temperature which has to be high enough for diffusion homogenization of carbon in austenite. In the deeper layers of the heat affected zone, the time of austenitizing and carbon diffusion rate allow for austenite homogenization only in the grains of pearlite. At the same time, low carbon austenite is formed from ferrite. As result of cooling, martensitic structure arises, with visible boundaries between the phases of former ferrite and pearlite. With larger depth and decreasing cooling rate in the heat affected zone, bainite and ferrite have been found in addition to martensite. In the subsequent layer of the heat affected zone, just before the core structure is reached, local presence of cooled pearlite can be found.

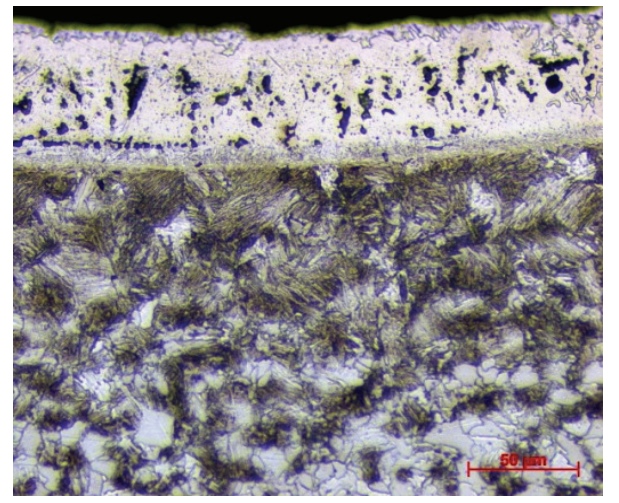

Fig. 5. Microstructure of the gouged $6 \mathrm{~mm}$ thick steel with the plasma current intensity of $15 \mathrm{~A}$, magnification $500 \mathrm{x}$.

When the melted metal zone is thicker (Fig. 3), its structure differs from that of a thin layer. Fig. 6 shows the results of an analysis of the linear distribution of elements in a sample with revealed thick zone of melted metal. Linear analysis (Fig. 6) shows that the thick zone of melted metal consists of two layers: outer one, with elevated nitrogen concentration and inner one, with elevated concentration of carbon. Probably, the elevated carbon concentration is a result of high processing temperature with the initial crystallizing outer layer of metal make good conditions of carbon diffusion from the deeper layer of the material to the inner layer of the melting zone. Analysis of the structures of that zone shows that its outer layer is low carbon strip martensite with nitrides (Fig 7a - top part); the inner layer of that zone is bainite with high dispersion (Fig. 7b).

It has also been determined that the melted zone shows significant porosity resulting from high nitrogen saturation. Due to the high cooling rate, nitrogen (N2) is trapped in the solidified metal during solidification [11]. It has been determined that the thicker melted zone the stronger is the phenomenon. The structure of the heat affected zone of samples with thick melted zone is similar to that of samples with thin melted zone. However, the thinner melted zone (higher plasma current intensity) the higher austenitizing temperature and longer its time, that is why austenite grows. Due to that, the beginning of the heat affected zone of the samples with thick melted zone has more coarse-grained structure than that of the samples with less thickness of the e. melted zone. 


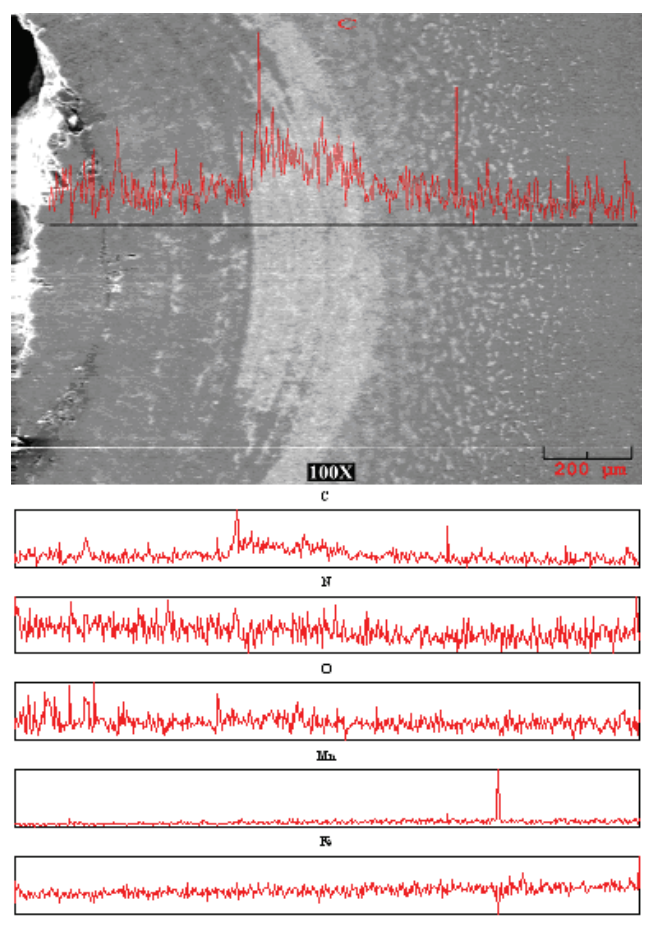

Fig. 6. Linear distribution of elements, C, N, O, Mn. Fe, on a cross section of a groove gouged in $6 \mathrm{~mm}$ thick steel with the current intensity of $25 \mathrm{~A}$.

a)

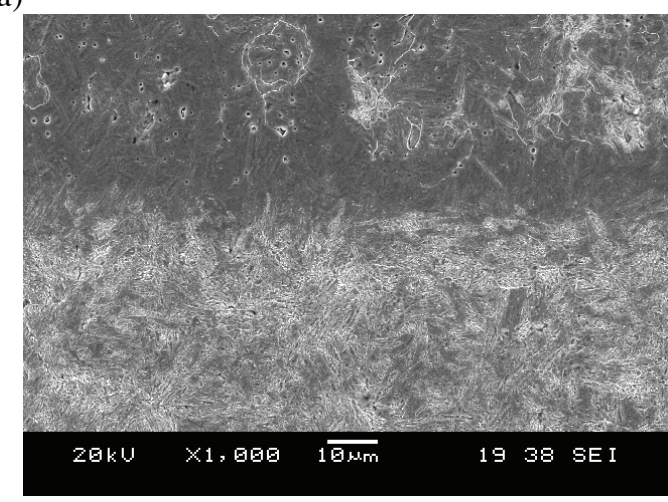

b)

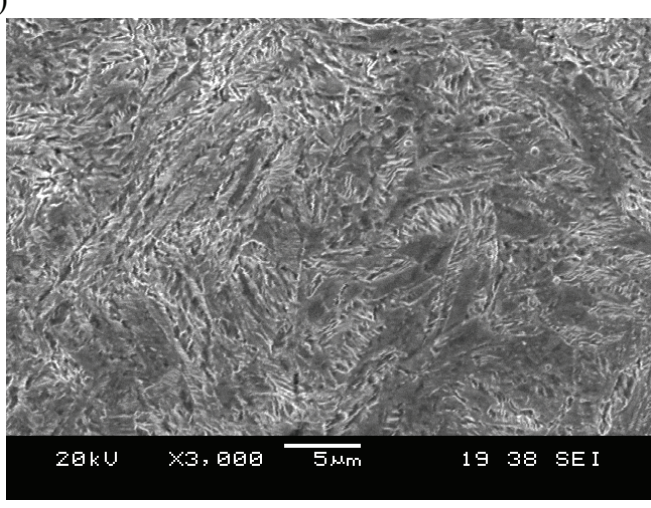

Fig. 7. Microstructure of the melted zone of $6 \mathrm{~mm}$ thick steel gouged with the plasma current intensity of $25 \mathrm{~A}$ : a) boundary of the outer and inner layer, magnification $1000 \mathrm{x}$; b) bainite of the inner layer of the melted zone, magnification 3000x.

\subsection{Measurement of hardness}

The purpose of hardness measurement was to determine the influence of the plasma current intensity on the changes of hardness in the heat affected zones of the gouged sheets with various thicknesses. On the groove cross section, from its bottom into the material, two rows of indentations have been made. The indentations have been made alternately at intervals of $50 \mu \mathrm{m}$. The values of hardness changes of all the nine samples are shown in Table 4. Hardness measurements are only those of the heat affected zone because no repeatable results could be obtained in the melted zones (porosity and brittleness).

Table 4. HV0.1 hardness distribution in the cross section of the gouged samples.

\begin{tabular}{|c|c|c|c|c|c|c|c|c|c|c|}
\hline \multirow{2}{*}{$\begin{array}{c}\text { SWC, } \\
\boldsymbol{\mu} \mathbf{m}\end{array}$} & \multicolumn{10}{|c|}{ No. samples } \\
\cline { 2 - 11 } & $\mathbf{1}$ & $\mathbf{2}$ & $\mathbf{3}$ & $\mathbf{4}$ & $\mathbf{5}$ & $\mathbf{6}$ & $\mathbf{7}$ & $\mathbf{8}$ & $\mathbf{9}$ \\
\hline & \multicolumn{10}{|c|}{ HV0.1 } \\
\hline $0^{*}$ & 371 & 525 & 609 & 450 & 483 & 490 & 519 & 558 & 714 \\
\hline 50 & 334 & 313 & 411 & 460 & 434 & 474 & 513 & 474 & 507 \\
\hline 100 & 281 & 310 & 344 & 468 & 430 & 434 & 513 & 496 & 513 \\
\hline 150 & 265 & 244 & 291 & 430 & 414 & 400 & 411 & 485 & 279 \\
\hline 200 & 236 & 229 & 276 & 331 & 344 & 291 & 470 & 294 & 334 \\
\hline 250 & 198 & 213 & 227 & 276 & 294 & 256 & 222 & 325 & 387 \\
\hline 300 & 197 & 207 & 203 & 212 & 248 & 224 & 197 & 313 & 302 \\
\hline 350 & 181 & 197 & 203 & 193 & 209 & 198 & - & 244 & 291 \\
\hline 400 & 177 & 193 & 196 & 179 & 196 & 189 & - & 227 & 250 \\
\hline 450 & - & 179 & 196 & - & 187 & 190 & - & 211 & 248 \\
\hline 500 & - & - & 194 & - & 181 & 182 & - & 198 & 212 \\
\hline 550 & - & - & 191 & - & - & - & - & - & 209 \\
\hline 600 & - & - & 189 & - & - & - & - & - & 200 \\
\hline 650 & - & - & 189 & - & - & - & - & - & - \\
\hline 700 & - & - & 182 & - & - & - & - & - & - \\
\hline *- first measurement located at the boundary of the melting \\
zone and the heat affected zone (SWC). \\
\hline
\end{tabular}

Considering the hardness distribution results (Table 4), it can be stated that, for the individual sheet thicknesses, the highest values of hardness have been obtained with the plasma current intensity of 25A. The highest value, $714 \mathrm{HV}$, has been recorded in sample (9) with the thickness of $16 \mathrm{~mm}$. In this case, high temperature of processing facilitates the processes of carbon diffusion in austenite while large cross section of the sheet ensures quick cooling. However, it has to be noted that those maximum values go rapidly down with larger depth. The maximum size of the heat affected zone, $700 \mu \mathrm{m}$, has been found in sample (3) with the least thickness and with the highest plasma current intensity. This is a result of high temperature of processing with relatively slow cooling. Similarly, the lowest size of the heat affected zone has been found in sample $7-$ the largest sheet thickness and the lowest value of the plasma current intensity. The influence of plasma current intensity on hardness changes in the heat affected zone has been shown in Fig. 8. The shape of the hardness distribution curves shows that increase of the plasma current intensity (with the same sheet thickness) causes extension of the heat affected zone and increase of the hardness values.

The thickness of plasma gouged sheet has also a significant influence on the hardness and size of the heat 
affected zone (Fig. 9). The recorded changes of hardness in the samples under examination, gouged with identical plasma current intensity, but with different thicknesses (Table 4) result from various rates of heat conduction into the material.

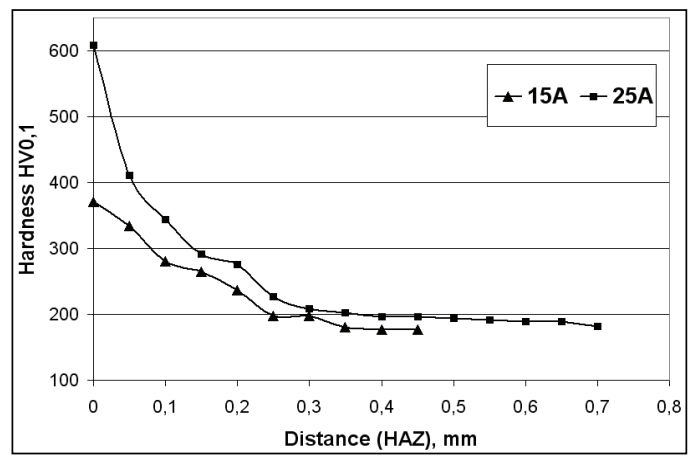

Fig. 8. The influence of the plasma current intensity on the hardness of heat affected zone in a $6 \mathrm{~mm}$ thick sheet.

The thickness of plasma gouged sheet has also a significant influence on the hardness and size of the heat affected zone (Fig. 9). The recorded changes of hardness in the samples under examination, gouged with identical plasma current intensity, but with different thicknesses (Table 4) result from various rates of heat conduction into the material.

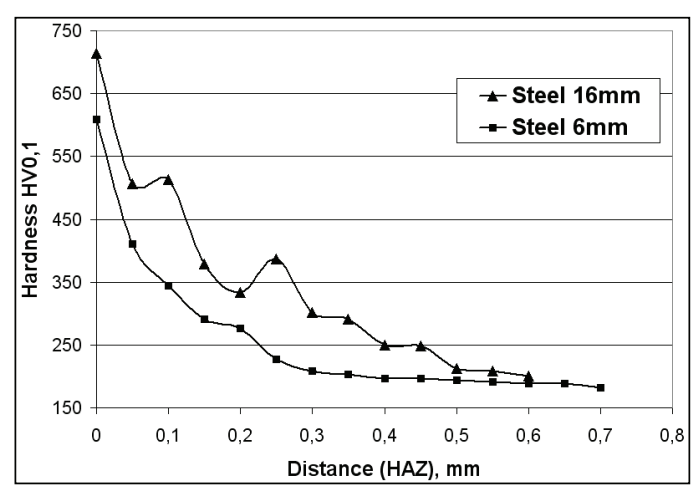

Fig. 9. The influence of the thickness of a sheet gouged with the plasma current intensity of $25 \mathrm{~A}$ on the hardness of the heat affected zone.

With a bigger cross section of the gouged sheet (Fig. 9 , curve - Steel $16 \mathrm{~mm}$ ), heat conduction is faster. Faster heat conduction results raising of the hardness value and reduction of the heat affected zone.

\section{Conclusions}

Basing on the performed tests, it has been stated that, in the process of gouging with the use of air plasma, the value of the plasma current intensity and the thickness of the material being processed significantly influence the properties of the top layer and the size of the executed grooves.

Analysis of the test results presented in the paper has made it possible to draw the following conclusions:

- with the increase of the sheet thickness, with the given plasma current intensity, the depth of the gouged grooves decreases. This results in reduction of the heat affected zone and growth of its hardness;

- $\quad$ increase of the plasma current intensity results in increasing the depth of gouging. This is a result of higher processing temperature which also facilitates the carbon diffusion processes and, consequently, causes increase of the heat affected zone hardness and size;

- increase of the plasma current intensity and gouging depth influences the growth of the melted zone and its structure. Thin melted zones (up to about 0.05 $\mathrm{mm}$ ) consist of low carbon martensite with iron nitrides. This structure is formed as result of quick cooling of decarburized but nitrogen saturated layer of metal. Thicker melted zones are characterized by laminar structure. In the outer layer, the structure of low carbon martensite with nitrides appears. In the inner layer, one can find bainite with higher carbon content arising due to slower cooling of that layer;

- the heat affected zones show structure gradually changing towards the material depth. Starting from the boundary of the melted zone, the following structures occur: martensite, martensite with bainite, and cooled pearlite and with secretions of ferrite, as well as ferrite with cooled pearlite. The depth of the heat affected zone and the width of the individual structural layers depends on the sheet thickness and the plasma current intensity.

\section{References}

1. S. Zaborski, T. Stechnij, Inżynieria Maszyn, E 16, 4, (2011)

2. M.S. Węglowski, T. Pfeifer, Biuletyn Instytutu Spawalnictwa, 1, (2014)

3. E. Tasak, Przegląd Spawalnictwa, 2-3, (1982)

4. T. Pfeifer, Budowa strukturalna i własności SWC elementów wycinanych plazmowo ze stali o wysokiej wytrzymałości - Part I. Stal, 7-8, (2013)

5. T. Pfeifer, Budowa strukturalna i własności SWC elementów wycinanych plazmowo ze stali o wysokiej wytrzymałości - Part II. Stal, 9-10, (2013)

6. J. Górka, R. Skiba, Przegląd spawalnictwa, 2, (2013)

7. R. Pakos, Przegląd spawalnictwa, 8, (2012)

8. D.J. Thomas, Int. J. Steel Struct. 11, 4, (2011)

9. R.W. Maruda, G.M. Krolczyk, M. Michalski, P. Nieslony, S. Wojciechowski, J. Mater. Eng. Perform. 26, 1, (2017)

10. T. Hamada, T. Kato, K. Aoyama, T. Aikawa, S. Asai, T. Kurokawa, H. Takebayashi, Weld. World 58, (2014)

11. H. Nohara, T. Jpn. Soc. Mech. Eng. 78, (2012) 